http://jmscr.igmpublication.org/home/ ISSN (e)-2347-176x ISSN (p) 2455-0450 crossref DOI: https://dx.doi.org/10.18535/jmscr/v8i7.83

\author{
Journal Of Medical Science And Clinical Research \\ IGM Publication \\ An official Publication of IGM Publication
}

\title{
Sexually transmitted infections in pregnancy: A 20 year retrospective clinico- epidemiological study from a tertiary care hospital, Kerala, South India
}

\author{
Authors \\ Sheena Ann Simon ${ }^{1 *}$, S Pradeep Nair ${ }^{2}$ \\ ${ }^{1}$ Assistant Professor, Department of Dermatology and Venereology, Government Medical College, \\ Thiruvananthapuram, Kerala \\ ${ }^{2}$ Professor, Department of Dermatology and Venereology, Government Medical College, \\ Thiruvananthapuram, Kerala. \\ *Corresponding Author \\ Dr Sheena Ann Simon
}

\begin{abstract}
Background: Sexually transmitted infections (STI's) in pregnancy are encountered worldwide and contribute to adverse fetal outcome.

Methodology: This is a 20 year retrospective record based study done in the STI clinic of our tertiary care center.

Results: There were 220 pregnant women with STI's, accounting for a frequency of $14.83 \%$. Some cases had multiple STI's and so the total number of STI's observed were 233. The mean age was 24.06 years. The majority of the pregnant women with STI's were primi (82.72\%). Majority of antenatal STI's were married (99.09\%), the source of contact was marital in 93.63\% and type of contact, heterosexual (100\%). Viral STI's were the most common, accounting for 136 cases (58.37\%). However syphilis was the commonest STI as a single group encountered in pregnant women, 89 cases (38.19\%). Condyloma acuminata accounted for 70 (30.04\%) and herpes genitalis 62 (26.61\%). Syphilis was again the commonest STI seen in the marital partner (59.02\%). The prevalence of genital discharge STI was only $3 \%$. There were no bacterial vaginosis or HIV cases.

Conclusions: This study showed a low prevalence of STI's in pregnant females. History of abortion was most common in pregnant women who had current syphilis (' $P$ ' $<0.001)$. Syphilis was the commonest STI as a single group, while viral STI's were the maximum. There were no cases of bacterial vaginosis and HIV infection .
\end{abstract}

Keywords: Pregnancy, Sexually transmitted infections, Syphilis.

\section{Introduction}

Sexually transmitted infections (STI's) occurring during pregnancy is considered as a medical complication of pregnancy. Pregnant women are at increased risk of STI's due to physiological changes that accompany pregnancy such as congestion of cervix, edema of vaginal mucosa and alteration in vaginal flora. ${ }^{1}$ STI's have been associated with a number of adverse pregnancy outcomes including congenital malformations, still birth, preterm delivery, low birth weight, postpartum sepsis and neonatal infections. Syphilis and herpes genitalis can cause congenital malformations. Gonnorrhea, chlamydial infections 
and bacterial vaginosis can cause premature rupture of membranes and contribute to morbidity and mortality of the fetus. Chlamydial infections are known to cause ectopic pregnancy and maternal condyloma acuminata (genital warts) can cause infantile laryngeal papillomas, while large genital warts can obstruct labor. In pregnancy, STI's should be managed with antimicrobial therapy, counseling, partner screening and safe sex advice. ${ }^{2}$

There is a paucity of literature regarding studies of STI's in pregnancy, moreso in South India, hence we conducted this study. The primary objective of this study was to find the frequency of STI's in pregnancy in our tertiary care STI clinic and the secondary objective was to study the epidemiological and clinical features of these STI's in pregnancy.

\section{Materials and Methods}

Study Design: This is a 20 year (1997-2016) retrospective descriptive record based study done in the STI clinic of our tertiary care center.

Study Population: All newly diagnosed cases of STI's in pregnancy who attended the urban STI clinic of our tertiary care center.

Data Collection: The data were collected from the standard pre-formatted STI cards of the clinic.

Inclusion Criteria: All new cases of pregnant women with STI in the study period. The demographic and clinical features of this cohort were studied in detail. Investigation details and partner details were also elicited from the STI cards. The final diagnosis was based on the clinical features and supporting laboratory evidence. Condyloma acuminata was diagnosed solely on clinical grounds. 2 years was taken as the cut off period to distinguish between early and late latent syphilis.

Exclusion Criteria: Pregnant women who acquired syphilis and hepatitis B through blood transfusion.

Laboratory Investigations: Syphilis was diagnosed by the VDRL and TPHA serological tests. Herpes genitalis was diagnosed by Tzanck smear and IgG and IgM ELISA for HSV 1 and 2. Hepatitis B was diagnosed by antigen estimation. Chancroid was diagnosed by gram stain and culture. Gonorrhea was diagnosed by gram stain and culture in chocolate agar. Trichomoniasis was diagnosed by normal saline wet smear examination and vaginal candidiasis by $10 \% \mathrm{KOH}$ mount test. Chlamydial infection was diagnosed on presumptive grounds. A finding of 5 or more pus cells in urine/vaginal discharge or urine sediment per oil immersion field without intra-cell diplococcic was indicative of chlamydial infection.

Statistical Methods: The data collected were analyzed in terms of descriptive statistics. The Chi square test was used to determine the statistical significance between variables and a ' $P$ ' value of $<0.05$ was considered to be significant.

Permission to conduct this study was given by the Institution Research committee and Human Ethical Committee of the college.

\section{Results}

A total of 1483 female STI patients attended our STI clinic in the study period (1997-2016). There were 220 pregnant women $(n=220)$ with STI's thus accounting for a frequency of $14.83 \%$. However some cases had multiple STI's and so the total number of STI's observed in this cohort were 233. The mean age was 24.06 years. The youngest was 18 years old and the oldest 37 years old. Commonest age group affected was 21- 30 years $(22.27 \%)$. An overwhelming majority of the cases in this cohort population of antenatal STI's were married $(99.09 \%)$, the source ofcontact was marital in $93.63 \%$ and type of contact, heterosexual (100\%). The prevalence of PMC/EMC was only $6.36 \%$ and history of STI's before pregnancy was observed in $16(7.27 \%)$. The majority of the pregnant women with STI's were primi $(82.72 \%)$. Early gestational age (13-28 weeks) accounted for the maximum number of cases $103(46.81 \%)$.

Viral STI's (Table 1) were the most common in this study accounting for 136 cases (58.37\%). 
However Syphilis was the commonest STI as a single group encountered in pregnant women, 89 cases $(38.19 \%)$. The pattern and frequency of STI's is given in Table 1 . The salient clinical features of syphilis is given in Table 2. The next most common STI's were condyloma acuminata (CA) and herpes genitalis (HG). The salient clinical features of CA and HG are given in Table 3.

30 cases $(13.63 \%)$ had a history of abortion and the pattern of STI's in these patients with abortion is given in Table 4. Syphilis was the commonest current STI in cases with history of abortion (23, $76.67 \%$ ) and this was statistically significant (' $P$ ' $<0.001)$. In cases with history of stillbirth (12 cases, $5.46 \%$ ), again syphilis was the commonest current STI (10/12 cases, 83.33\%). 61 cases of the married partner (husband) had clinical evidence of STI at the time of presentation of the antenatal cases in the STI clinic. History of premarital contact/extramarital contact (PMC/EMC) was present in 63 cases of the marital partner (28.63\%). Syphilis was again the commonest STI seen in the marital partner $(59.02 \%)$. The pattern of STI's in themarital partner (husband) is given in Table 5.

Table 1: The pattern of STI's and their frequency $(\mathrm{n}=233)^{*}$

\begin{tabular}{|l|c|c|}
\hline STI & Frequency & Percentage \\
\hline Syphilis & 89 & $38.19 \%$ \\
\hline Condyloma acuminata & 70 & $30.04 \%$ \\
\hline Herpes genitalis & 62 & $26.61 \%$ \\
\hline Vaginal candidiasis & 4 & $1.72 \%$ \\
\hline Genital molluscum contagiosum & 3 & $1.29 \%$ \\
\hline Chancroid & 1 & $0.43 \%$ \\
\hline Gonorrhoea & 1 & $0.43 \%$ \\
\hline Non-gonococcal urethritis & 1 & $0.43 \%$ \\
\hline Trichomonas vaginalis & 1 & $0.43 \%$ \\
\hline Hepatitis B & 1 & $0.43 \%$ \\
\hline
\end{tabular}

*The number of STI's is more than the number of patients due to some patients having multiple STI's.

Table 2. Salient clinical features of syphilis

\begin{tabular}{|l|c|c|c|c|}
\hline Total number & Types of syphilis & Mean Age & Secondary syphilis & Mean VDRL Titer \\
\hline 89 & Secondary 11(12.36\%) & 24.47 years & Papulosquamous & Secondary $1: 32$ \\
& Early latent 25(28.09\%) & & $6(54.54 \%)$ & Early latent $1: 4$ \\
& Late latent 53(59.55\%) & & Condyloma lata + & Late latent $1: 4$ \\
& & & Lymphadenopathy & \\
\hline
\end{tabular}

Table 3. Salient clinical features of condyloma acuminata and herpes genitalis

\begin{tabular}{|c|c|c|c|c|c|c|}
\hline STI & Total Number & Mean age & $\begin{array}{c}\text { Mean } \\
\text { Incubation } \\
\text { period }\end{array}$ & Commonest site & $\begin{array}{l}\text { Commonest } \\
\text { multiple sites }\end{array}$ & $\begin{array}{c}\text { Extra- } \\
\text { genital sites }\end{array}$ \\
\hline $\begin{array}{l}\text { Condyloma } \\
\text { acuminata }\end{array}$ & 70 & $\begin{array}{l}23.48 \\
\text { years }\end{array}$ & 2.72 months & $\begin{array}{c}\text { Labia majora } \\
46(65.71 \%)\end{array}$ & $\begin{array}{c}\text { Labia majora }+ \\
\text { Labia minora } \\
23(32.86 \%)\end{array}$ & $\begin{array}{c}\text { Anal } \\
\text { Perineum } \\
\text { Thighs } \\
11(15.71 \%) \\
\end{array}$ \\
\hline $\begin{array}{l}\text { Herpes } \\
\text { genitalis }\end{array}$ & $\begin{array}{c}62 \\
\text { Primary } \\
51(82.26 \%) \\
\text { Recurrent } \\
11(17.74 \%) \\
\end{array}$ & $\begin{array}{l}24.52 \\
\text { years }\end{array}$ & 8.5 days & $\begin{array}{c}\text { Labia majora } \\
42(67.74 \%)\end{array}$ & $\begin{array}{c}\text { Labia majora }+ \\
\text { Labia minora } \\
26(41.93 \%)\end{array}$ & $\begin{array}{c}\text { Anal } \\
\text { Perineum } \\
4(6.45 \%)\end{array}$ \\
\hline
\end{tabular}

Table 4. Pattern of STI's in patients with history previous of abortion $(n=30)$

\begin{tabular}{|l|c|c|}
\hline STI & Number & Frequency $(\%)$ \\
\hline Secondary syphilis & 2 & $6.67 \%$ \\
\hline Early latent & 8 & $26.67 \%$ \\
\hline Late latent & 14 & $46.67 \%$ \\
\hline Herpes genitalis & 4 & $13.33 \%$ \\
\hline Condylomaaccuminata & 2 & $6.67 \%$ \\
\hline
\end{tabular}

Table 5 Pattern of STI's in marital partner $(\mathrm{n}=61)$

\begin{tabular}{|l|c|c|}
\hline STI & Number & Frequency (\%) \\
\hline Secondary syphilis & 3 & $4.92 \%$ \\
\hline Early latent & 6 & $9.84 \%$ \\
\hline Late latent & 27 & $44.26 \%$ \\
\hline Herpes genitalis & 13 & $21.31 \%$ \\
\hline Condyloma accuminata & 10 & $16.39 \%$ \\
\hline NGU & 2 & $3.28 \%$ \\
\hline
\end{tabular}




\section{Discussion}

This is a 20 year retrospective study in a cohort of antenatal population with STI's who attended the STI clinic of our tertiary care hospital. A total of 1483 women with STI attended our clinic during the study period, out of which there were 220 antenatal cases with STI's. Thus this accounted for $14.83 \%$ of the cases.However some cases had multiple STI's and hence the total number of STI's were 233. But in a study done in the island Vanuatu, $13 \%$ pregnant women had more than one STI. ${ }^{3}$ The prevalence of STI's in pregnancy varies from country to country. A national community based study of STI in pregnant women by NACO showed a prevalence of $32.5 \%$. The prevalence of STI's in pregnant women in developed countries varies from $0.2 \%$ to $15 \%$. ${ }^{4,5}$ And the prevalence in developing countries range from $1.7 \%$ to $53.4 \% .{ }^{6}$ Hence, the prevalence in this study was less than other Indian studies. This can be attributed to the very high health indices and treatment seeking behavior of patients in this state due to the very high literacy in females.

The majority of the cases in this study, $(69.1 \%)$ belonged to the age < than 25 years (mean age 24.06 years). This is in conformance with the studyby Barney OJ et al. ${ }^{7}$ Shah et al also found that the prevalence of STIs reduced with advanced age. ${ }^{8}$ This relatively young age group in antenatal women in India is due to early age at which they marry and subsequent exposure to sexually transmitted agents from their husbands. Majority of the cases in this cohort population of antenatal STI's were married $(99.09 \%)$, the source of contact was marital in $93.63 \%$ and type of contact, heterosexual (100\%). The prevalence of PMC/EMC in this study was only $6.36 \%$. This is a unique feature of antenatal STI's and STI's in females in most parts of India.Social norms and cultural taboos in Indian women refrain themselves from PMC/EMC unlike their western counterparts. According to a study done in an African country among females, the prevalence of STIs was significantly higher among single women $(26.4 \%)$ as compared to married women
$(11.2 \%) .{ }^{9}$ Primi accounted for the majority of STI's in this study $(82.72 \%)$. In contrast, STIs were reported more in multigravida in thestudy done by Apparao $\mathrm{S}$ et al. ${ }^{1}$ In the present study, early gestational age (13-28 weeks) accounted for the maximum number of cases $(46.81 \%)$. Contrary to this, in the study done in western India,the risk of STIwas high in those presented in third trimester.

History of abortion was present in $13.63 \%$ of the antenatal cases and in majority of these patients (76.67\%), the current STI was syphilis (Table 4). This was statistically significant (' $P$ ' $<0.001$ ). In cases with history of stillbirth, again syphilis was the commonest current STI (83.33\%). Syphilis is the most common STI to cause abortions and stillbirths and probably the cause of abortions and stillbirths in these patients, previously was undetected syphilis. ${ }^{10}$ And in the study by Torres RG et al, out of 268 pregnant women with syphilis, only $1.5 \%$ patients had miscarriage and $3.4 \%$ had fetal losses. ${ }^{11}$ Even though viral STI's $(57.94 \%)$ as a group were the most common encountered in this cohort of antenatal women, the commonest STI as a single group was syphilis (38.19\%). This is a unique finding of this study as most other Indian studies and western studies indicate either herpes genitalis or condyloma acuminata as the single most common STI in pregnant women. The prevalence of syphilis in other studies range from $2.4 \%$ to $17 \%$. ${ }^{6,12}$

Latent syphilis was the commonest type of syphilis seen in antenatal women in this study (87.64\%). Itis the commonest type of syphilis seen in this state in all populationgroups, which is unique to this state. ${ }^{13}$ This is because a substantial proportion of males in this state migrate to Middle East countries for better job prospects where screening for VDRL and TPHA is compulsory and therefore previously undetected syphilis is picked up. This prompts for investigations in their spouses, thereby detecting syphilis in previously undiagnosed females in both pregnant and nonpregnant population, as the disease is already transmitted to them without their knowledge. The 
relative paucity of early symptomatic syphilis in this study is due to the concept of "happenstance treatment", where frequent intake of penicillin containing antibiotics for unrelated conditions may partially or completely cure syphilis and hence only latent syphilis is encountered, which is accidently detected during antenatal check upor for screening purposes. ${ }^{13}$ Papulo-squamous syphilis was the commonest type $(54.54 \%)$ to be seen in the secondary syphilis cases. This is now the general trend seen in India regarding early syphilis. In the marital partner (husband) of the antenatal women the commonest STI again was syphilis at the time of diagnosis of STI in their pregnant wife, accounting for $59.02 \%$ (Table 5) .

The prevalence of CA in this study was $30.04 \%$. The risk of condyloma acuminata in pregnancy is two fold.It is a well known fact the even small CA not evident clinically, enlarges duringpregnancy due to increased vascular flow and hormonal changes and this prompts the patient to seek medical care. ${ }^{14}$ The prevalence of HPVinfection is shown as around $46 \%$ during pregnancy. ${ }^{15}$ The prevalence of HG in this study was $26.61 \%$. This is comparable with most other studies where the prevalence ranged from $25-36 \%{ }^{2,16}$

The prevalence of genital discharge STI in this study was low when compared to other studies accounting for only $3 \%$. This could be attributed to the "syndromic treatment" advocated by the Gynaecology department which also sees and treats genital discharge diseases and so probably less cases are referred to our department. The prevalence of genital discharge inpregnancy in other studies varies from $31.5-56.3 \%{ }^{3,17}$ Vaginal candidiasis (VC) was the commonest genital discharge STI seen in this study accounting for $1.72 \%$. In a study done in Nigeria, prevalence of genital candida accounted for $60.8 \%$ among pregnant women. ${ }^{17}$ However caution should be exercised in labelling $\mathrm{VC}$ as a STI in pregnant women, as $\mathrm{VC}$ is very common in pregnancy due to relative immunosuppression and hormonal imbalance.
The prevalence of gonorrhea $(0.43 \%)$, NGU (chlamydial) infection $(0.43 \%)$ and trichomonas vaginalis (TV), $0.43 \%$ in this study was also low compared to other studies. This institute does not have advance equipments like PCR or serological tests to diagnose Chlamydia infections and so it is possible that some cases were missed, especially subclinical cases. The prevalence of TV reported by Schonfeld A et al was $5.3 \% .{ }^{18}$ In the study done in Ethiopia, the commonest discharge diseasewas chlamydial urethritis in pregnant women, $9.8 \%$, while gonorrhea accounted for $4.3 \%{ }^{18}$ There were no cases of BV in our study. In a study done in Nairobi, East Africa, Bacterial vaginosis (BV) was the commonestgenital discharge STI accounting for 37\%. ${ }^{19}$ This variation in different countries and regions of agents causing genital discharge STI could be due to the prevalence of these agentsvarying from region to region in the population at risk. ${ }^{6,19}$ In the present study there were no HIV cases in the antenatal cohort, even though there were HIV cases in the nonpregnant females who attended our STI clinic.

\section{Conclusions}

This study showed a low prevalence of STI's in pregnant females and marital contact was the commonest source of acquiring STI. Age less than 25 years, primi and early gestational age were the commonest affected. History of abortion was common in pregnant women who had current syphilis (' $P$ ' <0/001). Syphilis was the commonest STI as a single group, while viral STI's were the maximum.Syphilis was the commonest STI in the marital partner and there were no cases of bacterial vaginosis and HIV in this study.

\section{Limitations of the Study}

Retrospective studies have inherent weakness. It is possible that the prevalence of STI in pregnant women in this study could not be the general trend in this state as this study was done in a tertiary care center where probably more cases were 
referred. It is possible that subclinical chlamydial cases were missed as there were no advanced equipments like PCR and serological tests to diagnose this STI in our institute.

\section{Source of Support: Nil}

Conflict of Interest: None Declared.

\section{References}

1. Apparao $P$ and Siddartha $P$. Seroprevalence of sexually transmitted diseases among pregnant women in a tertiary care hospital. Int $\mathbf{J}$ Res Prof 2016;2:40-2.

2. Allstaff $\mathrm{S}$ and Wilson J. The management of sexually transmitted infections in pregnancy. The Obstet Gynecol 2012; 14:25-32.

3. Sullivan EA, Abel M, Tabrizi S, Garland SM, Grice A, Poumerol G, et al. Prevalence of sexually transmitted infections among antenatal women in Vanuatu, 1999- 2000. Sex Transm Dis 2003;30:362- 6 .

4. Sharma S, Gugnani K, Klug L, Saxena S. Sexually transmitted diseases in pregnancy in urgent care setting. J Clin GynecolObstet2014;3:123-28.

5. Ekeroma AJ, Pandit L, Bartley C, Ilkenasio-Thorpe B, Thompson JMD. Screening for sexually transmitted infections in pregnancy at Middlemore Hospital, 2009. N Z Med J 2012;125:2330.

6. Mullick S, Watson-Jones D, Bebsinska M, Mabey D. Sexually transmitted infections in pregnancy: prevalence, impact on pregnancy outcomes, and approach to treatment in developing countries. Sex Transm Infect 2005;81:294-302.

7. Barney OJ and Nathan M. Study of the prevalence of sexually transmitted infections and related conditions in pregnant women attending a sexual health service. Int J STD AIDS 2005;16:353-56.
8. Shah M, Deshmukh S, Patel SV, Mehta K, Marfatia Y. Validation of vaginal discharge syndrome among pregnant women attending obstetrics clinic, in the tertiary hospital of Western India. Indian $\mathbf{J}$ Sex Transm Dis 2014;35:118-23.

9. Ginindza TG, Stefan CD, TsokaGwegweni JM, Dlamini X, Jolly PE, Weiderpass E et al. Prevalence and risk factors associated with sexually transmitted infections (STIs) among women of reproductive age in Swaziland. Infectious Agents and Cancer 2017; 12:29. doi. 10.1186/s13027-017-0140-y.

10. Doroschenko A, Sherrard J, Pollard AJ. Syphilis in pregnancy and the neonatal period. Int J STD AIDS 2006;17:221-28.

11. Torres RG, Mendonça ALN, Montes GC, Manzan JJ, Ribeiro JU, Paschoin MC.Syphilis in Pregnancy: The Reality in a Public Hospital. Rev. Bras. Ginecol. Obstet 2019 :41 (2).doi.org/10.1055/s0038-1676569.

12. Costa MC, Demarch EB, Azulay DR, Perisse ARS, Dias MFRG, Nery JAD.An Bras Dermatol 2010;85:767-85.

13. Nair SP. A study of the changing trends of sexually transmitted infections in the state of Kerala. Indian $\mathbf{J}$ Sex Trans Dis 2012;33:64-5.

14. Singhal P, Naswa S, Marfatia YS. Pregnancy and sexually transmitted viral infections. Indian $\mathbf{J}$ Sex Transm Dis 2009;30:71-8.

15. Yavuzcan A, ÇaLlar M, Turan H, Tekin A, Topuz S, Yavuzca G et al.The Treatment of Giant Periurethral Condyloma in Pregnancy Using an Ultrasonic Thermal Scalpel: A Case Reportand New Single Session Treatment Option.Case reports in Obstetrics \&Gynaecology2015 ;doi.org /10.1155/2015/792412.

16. Brown ZA, Selke S, Zeh J, Kopelman J, Maslow A, Ashley RL, et al. The acquisition of herpes simplex virus during 
pregnancy. N Engl J Med 1997;337:509-

15.

17. Nnadi DC, Singh S. The prevalence of genital Candida species among pregnant women attending antenatal clinic in a tertiary health center in North-west Nigeria. Sahel Med J 2017;20:33-7.

18. Schonfeld A, Feldt T, Tufa TB, Orth HM, Fuchs A, Mesfun MG, et al. Prevalence and impact of sexually transmitted infections in pregnant women in central Ethiopia. IntJ STD AIDS2017;29:251-58.

19. Marx G, John-Stewart G, Bosire R, Wamalwa D, Otieno P, Farquhar C.Diagnosis of sexually transmitted infections and bacterial vaginosis among HIV-1-infected pregnant women in Nairobi. Int J STD AIDS 2010;21: 549-52. 